\title{
Necessary and Sufficient Conditions for The Solutions of Linear Equation System
}

\author{
Syarat Perlu dan Syarat Cukup Penyelesaian \\ Sistem Persamaan Linear atas Semiring
}

\author{
Gregoria Ariyanti*
}

\begin{abstract}
A Semiring is an algebraic structure $(S,+, \times)$ such that $(S,+)$ is a commutative Semigroup with identity element $0,(S, \times)$ is a Semigroup with identity element 1 , distributive property of multiplication over addition, and multiplication by 0 as an absorbent element in $S$. A linear equations system over a Semiring $S$ is a pair $(A, b)$ where $A$ is a matrix with entries in $S$ and $b$ is a vector over $S$. This paper will be described as necessary or sufficient conditions of the solution of linear equations system over Semiring $S$ viewed by matrix $X$ that satisfies $A \times X \times$ $A=A$, with $A \in M_{m \times n}(S)$. For a matrix $X$ that satisfies $A \times X \times A=A$, a linear equations system $A \times x=b$ has solution $x=X \times b+(I-X \times A) \times$ with arbitrary $h$ in $S$ if and only if $A \times X \times b=b$.
\end{abstract}

Keywords: $\quad$ semiring, linear equations system, matrix

\begin{abstract}
Abstrak
Semiring merupakan salah satu struktur aljabar $(S,+, \times)$ dengan $(S,+)$ merupakan Semigrup komutatif dengan elemen identitas $0,(S, \times)$ merupakan Semigrup dengan elemen identitas 1 , sifat distributif perkalian atas penjumlahan, dan perkalian dengan 0 sebagai elemen penyerap (absorbent) dalam S. Suatu sistem persamaan linear atas Semiring $S$ adalah pasangan $(A, b)$ dengan $A$ adalah matriks dengan entri dalam $S$ dan $b$ adalah vektor dalam $S$. Dalam tulisan ini dikembangkan syarat perlu atau cukup dari penyelesaian sistem persamaan linear atas Semiring $S$ dengan meninjau matriks $X$ yang memenuhi $A \times X \times A=A$, dengan $A \in$ $\mathrm{M}_{\mathrm{m} \times \mathrm{n}}(\mathrm{S})$. Untuk matriks $\mathrm{X}$ yang memenuhi $\mathrm{A} \times \mathrm{X} \times \mathrm{A}=\mathrm{A}$, sistem persamaan linear $\mathrm{A} \times \mathrm{X}=$ b mempunyai penyelesaian $\mathrm{x}=\mathrm{X} \times \mathrm{b}+(\mathrm{I}-\mathrm{X} \times \mathrm{A}) \times \mathrm{h}$ dengan $\mathrm{h}$ sebarang anggota $\mathrm{S}$ jika dan hanya jika $\mathrm{A} \times \mathrm{X} \times \mathrm{b}=\mathrm{b}$.
\end{abstract}

Kata kunci:semiring, sistem persamaan linear, matriks

\section{PENDAHULUAN}

Ilmu Matematika meliputi beberapa bidang, di antaranya Aljabar, Analisis, dan Statistika. Bidang Aljabar meliputi beberapa struktur aljabar, diantaranya Ring. Suatu himpunan tak kosong

*Prodi Pendidikan Matematika, Universitas Katolik Widya Mandala Surabaya Kampus Madiun, Email: ariyanti_gregoria@yahoo.com 


\section{Gregoria Ariyanti}

$R$ yang dilengkapi dengan dua operasi biner yaitu $*$ dan $\circ$ disebut Ring jika memenuhi sifat-sifat: $(R, *)$ merupakan Grup komutatif; tertutup terhadap operasi biner $\circ$; asosiatif terhadap operasi biner $\circ$; dan terhadap kedua operasi biner $*$ dan $\circ$ bersifat distributif. Dengan penambahan sifat pada Ring diperoleh Ring khusus yang disebut Lapangan (Field), yaitu ring $(F, *, \circ)$ yang memiliki sifat: komutatif terhadap operasi biner $\circ$; mempunyai elemen satuan terhadap operasi biner $\circ$; dan setiap elemen yang bukan elemen nol mempunyai invers terhadap operasi biner $\circ$.

Jika syarat suatu Ring diperlemah, akan muncul struktur aljabar lain, yaitu Semiring. Artinya, jika beberapa syarat Ring ditiadakan, maka struktur aljabar yang terbentuk adalah Semiring. Salah satu permasalahan atau aplikasi yang sering dijumpai dalam matematika adalah menyelesaikan Sistem Persamaan Linear. Sistem persamaan linear yang telah dikembangkan oleh para peneliti adalah sistem persamaan linear atas Lapangan (Field) yang meliputi bilangan real $\mathbb{R}$ atau bilangan kompleks $\mathbb{C}$. Pada penelitian lain, objek penelitian diperluas bukan lagi atas Lapangan, tetapi atas Ring komutatif. Matriks atas Ring komutatif telah dibahas oleh Brown [4] dan sistem persamaan linear atas Ring komutatif telah dibahas oleh Brewer, dkk. [3].Asumsi perluasan dari Lapangan ke Ring komutatif tidak mengubah keberlakukan sifat dan definisi secara umum.

Sistem persamaan linear terbagi menjadi sistem persamaan linear homogen dan tak homogen. Suatu sistem persamaan linear mempunyai tiga kemungkinan penyelesaian, yaitu mempunyai penyelesaian tunggal, penyelesaian banyak, dan tidak mempunyai penyelesaian. Eksistensi penyelesaian tersebut sangat tergantung dari sistem persamaan linear itu sendiri.

Dalam tulisan ini, dikembangkan syarat perlu atau cukup penyelesaian sistem persamaan linear atas Semiringserta dibatasi pada sistem persamaan linear tak homogen. Pada bagian kedua dalam tulisan ini, diuraikan pembentukan sistem persamaan linear atas Lapangan dan teori dasar dari Semiring. Sedangkan dalam bagian ketiga dibahas syarat perlu atau syarat cukup penyelesaian sistem persamaan linear tak homogen atas Semiring.

\section{SISTEM PERSAMAAN LINEAR DAN SEMIRING}

Diberikan sistem persamaan linear $A \times x=B \quad$ dengan matriks $=\left(a_{i j}\right) \in M_{m \times n}(\mathbb{R})$, $B=\left(\begin{array}{llll}b_{1} & b_{2} & \cdots & b_{m}\end{array}\right)^{T} \in \mathbb{R}^{m}, x=\left(\begin{array}{llll}x_{1} & x_{2} & \cdots & x_{n}\end{array}\right)^{T} \in \mathbb{R}^{n}$, dan $\mathbb{R}$ lapangan himpunan bilangan real. Persamaan tersebut dikatakan mempunyai penyelesaian di $\mathbb{R}^{n}$, jika ada vektor $\xi \in \mathbb{R}^{n}$ sehingga $A \xi=B$. Jika $B=0$ maka sistem persamaan linear $A \times x=0$ disebut sistem persamaan linear homogen. Sistem persamaan linear homogen selalu mempunyai paling sedikit satu penyelesaian yaitu $\xi=0=\left(\begin{array}{llll}0 & 0 & \ldots & 0\end{array}\right)^{T} \in \mathbb{R}^{n}$. Penyelesaian $\xi=0$ demikian disebut penyelesaian trivial dari sistem persamaan linear $A \times x=0$. Sedangkan, vektor $\xi \in \mathbb{R}^{n}$ disebut penyelesaian tak trivial dari sistem persamaan linear $A \times x=0$ jika $\xi \neq 0$ dan $A \times \xi=0$.

Dari sistem persamaan linear $A \times X=B$ dapat dinyatakan dalam bentuk $(A \mid B)$ yang disebut matriks diperluas (augmented matrix) [1]. Entri-entri dari matriks diperluas (augmented matrix) dapat dioperasikan sehingga diperoleh matriks yang lebih sederhana melalui operasi baris elementer. Dengan serangkaian operasi baris elementer yang dikerjakan pada suatu matriks, akan diperoleh matriks dalam bentuk eselon baris tereduksi. Untuk suatu matriks $A$, simbol $I_{t}(A)$ melambangkan bentuk eselon baris tereduksi yang berasal dari matriks $A$ melalui serangkaian operasi baris elementer [1].

Definisi 2.1.[5] Diberikan E matriks bentuk eselon baris tereduksi yang diperoleh dari matriks A melalui serangkaian operasi baris elementer. Rank dari A didefinisikan sebagai banyaknya baris tak nol di dalam E. Dinotasikan dengan $r k(A)$. 


\section{Gregoria Ariyanti}

Syarat perlu dan cukup sistem persamaan linear homogen mempunyai penyelesaian tak trivial dinyatakan oleh Meyer [5] berikut.

Teorema 2.2.[5]Diberikan $A=\left(a_{i j}\right) \in M_{m \times n}(\mathbb{R})$. Sistem persamaan linear homogen $A \times X=$ 0 mempunyai penyelesaian tak trivial jika dan hanya jika $r k(A)<n$.

Berikut ini diberikan definisi dan sifat-sifat Semiring yang merupakan generalisasi dari suatu Semigroup berdasarkan Poplin dalam Ariyanti dkk. [2].

Definisi 2.3.[2]Semigrup $S$ adalah himpunan tak kosong yang dilengkapi dengan operasi biner * yang bersifat asosiatif, yaitu untuk setiap $x, y, z \in S$ berlaku $x *(y * z)=(x * y) * z$.

Lebih lanjut lagi, Poplin memberikan definisi sebagai berikut.

Definisi 2.4.[2]Semiring adalah suatu himpunan tak kosong $S$ dilengkapi dua operasi biner, penjumlahan $(+)$ dan perkalian $(\times)$, yang mempunyai sifat-sifat sebagai berikut.

a. Operasi + adalah komutatif dan asosiatif

b. Operasi $\times$ adalah asosiatif dan distributif terhadap +

c. Himpunan $S$ mempunyai sebuah elemen nol $\theta$ yang sekaligus elemen penyerap (absorbsi).

d. Himpunan $S$ mempunyai sebuah elemen satuan e dengan $e \neq \theta$.

Seperti halnya di dalam struktur Grup dan Ring, sifat komutatif juga berlaku pada Semiring tertentu. Demikian juga, Poplin menyatakan bahwa terhadap penjumlahan memenuhi sifat idempoten [2]. Perbedaan utama antara struktur Semiring dan struktur Ring dapat diketahui dari eksistensi elemen invers terhadap operasi penjumlahan.

Diberikan $S$ semiring komutatif dengan elemen nol 0 dan elemen satuan 1, bilangan bulat positif $n$, dan $M_{n}(S)$ himpunan dari semua matriks $n \times n$ atas $S$. Terhadap operasi penjumlahan, $M_{n}(S)$ bersifat komutatif. Untuk $A \in M_{n}(S)$ dan $i, j \in\{1,2, \ldots, n\}$, diberikan $A_{i j}$ unsur (entry) dari $A$ dalam baris ke- $i$ dan kolom ke-j. Transpos dari $A \in M_{n}(S)$ dinotasikan $A^{t}$, dengan $A_{i j}^{t}=A_{j i}$ untuk setiap $i, j \in\{1,2, \ldots, n\}$. Akibatnya untuk $A, B \in M_{n}(S)$ berlaku sifat $\left(A^{t}\right)^{t}=$ $A,(A+B)^{t}=A^{t}+B^{t} \operatorname{dan}(A B)^{t}=B^{t} A^{t}$. Di dalam Semiring, elemen-elemen atas Semiring mempunyai invers terhadap operasi + , sehingga dapat didefinisikan determinan suatu matriks atas Semiring $S$. Oleh karena itu, determinan matriks atas Semiring $S$ dapat dikarakteristikkan dengan permutasi. Adapun definisi permutasi diberikan sebagai berikut.

Definisi 2.5.[1]Suatu permutasi merupakan suatu himpunan bilangan bulat yang disusun dalam suatu urutan tanpa penghilangan atau pengulangan.

Berdasarkan Definisi 2.5, dapat dijelaskan pernyataan berikut. Diberikan $\mathcal{X}=\{1,2, \ldots, n\}$. Suatu fungsi $\sigma: X \rightarrow X$ disebut permutasi pada $n$ elemen jika $\sigma$ merupakan fungsi satu-satu dan onto. Selanjutnya, himpunan semua permutasi dari himpunan $\mathcal{X}=\{1,2, \ldots, n\}$. dinyatakan dengan $x_{n}$.

Definisi 2.6.[1] Suatu matriks $n \times n$ disebut matriks elementer jika diperoleh dari matriks identitas yang dibentuk dari operasi baris elementer tunggal. 


\section{Gregoria Ariyanti}

\section{HASIL DAN PEMBAHASAN}

Berdasarkan sifat-sifat yang dimiliki matriks atas Semiring dan generalisasi dari permutasi yang terdapat pada aljabar konvensional, maka diperoleh karakteristik permutasi suatu matriks atas Semiring.

Definisi 3.1. Matriks A disebut matriks permutasi jika setiap entri dari A adalah 0 atau 1 dengan setiap baris dan setiap kolom meтuat tepat satu elemen 1 dan elemen yang lainnya adalah 0.

Dari Definisi 3.1 dapat direpresentasikan sebagai berikut. Jika $x:\{1,2, \ldots, n\} \rightarrow\{1,2, \ldots, n\}$ suatu permutasi, maka didefinisikan matriks permutasi $P_{\sigma}=\left[p_{i j}\right]$ dengan $p_{i j}=\left\{\begin{array}{l}1 ; i=\sigma(j) \\ 0 ; i \neq \sigma(j)\end{array}\right.$.

Definisi 3.2. Untuk $\lambda_{1}, \lambda_{2}, \ldots, \lambda_{n} \in S, \lambda_{i} \neq 0$, didefinisikan matriks diagonal sebagai

$$
D\left(\lambda_{i}\right)=\left(\begin{array}{cccc}
\lambda_{1} & 0 & 0 & 0 \\
0 & \lambda_{2} & 0 & 0 \\
\vdots & \vdots & \ddots & \vdots \\
0 & 0 & \cdots & \lambda_{n}
\end{array}\right) .
$$

Lemma 3.3.Diberikan $P_{\sigma}$ matriks permutasi atas Semiring $S$. Invers dari $P_{\sigma}$ adalah transpos dari $P_{\sigma}$.

Contoh 3.4. Diberikan $P_{\sigma}=\left(\begin{array}{lll}0 & 0 & 1 \\ 1 & 0 & 0 \\ 0 & 1 & 0\end{array}\right)$. Diperoleh $\left(P_{\sigma}\right)^{-1}=\left(P_{\sigma}\right)^{T}=\left(\begin{array}{lll}0 & 1 & 0 \\ 0 & 0 & 1 \\ 1 & 0 & 0\end{array}\right)$, karena $P_{\sigma} \times$ $\left(P_{\sigma}\right)^{-1}=\left(\begin{array}{lll}1 & 0 & 0 \\ 0 & 1 & 0 \\ 0 & 0 & 1\end{array}\right)$

Karena melalui serangkaian operasi baris elementer pada matriks $A$ atas Semiring $S$ dapat diperoleh bentuk eselon baris tereduksi dari matriks $A$, maka dapat ditinjau banyaknya baris tak nol pada matriks tereduksi tersebut.

Definisi 3.5.Diberikan $A \in M_{m \times n}(S)$ dengan $S$ semiring. Rank $A$, dilambangkan $\operatorname{rank}(A)$, adalah banyak baris yang tidak nol dalam bentuk eselon baris tereduksi dari matriks $A$.

Dalam mengkonstruksi syarat perlu atau syarat cuku untuk penyelesaian sistem persamaan linear $A \times x=b$ digunakan matriks $A$ sehingga $A \times X \times A=A$. Secara umum, dari matriks $A \in M_{m \times n}(S)$, dapat diperoleh matriks lain yang merupakan hasilkali matriks-matriks elementer dan matriks $A$ yang dinyatakan dalam teorema berikut.

Teorema 3.6. Untuk $A \in M_{m \times n}(S)$ dengan $\operatorname{rank}(A)=r$, maka terdapat matriks $P$ dan $Q$ yang merupakan hasilkali matriks-matriks elementer sehingga

$$
P \times A \times Q=\left(\begin{array}{cc}
I_{r} & 0 \\
0 & 1
\end{array}\right)
$$

dengan $I_{r}$ matriks identitas $r \times r$. 


\section{Gregoria Ariyanti}

Bukti. Diberikan $E_{A}$ bentuk eselon baris tereduksi dari matriks $A$. Oleh karena itu terdapat matriks $P$ hasil kali matriks-matriks elementer sehingga $P \times A=E$. Diketahui $\operatorname{rank}(A)=r$, sehingga $E_{A}$ mempunyai $r$ baris pertama yang tidak nol. Akibatnya, banyaknya kolom yang memuat unsur pertama tidak nol adalah $r$. Kolom-kolom tersebut dimisalkan $i_{1}, i_{2}, \cdots, i_{r}$, di mana untuk $1 \leq s \leq r$, kolom ke- $i_{s}$ mempunyai unsur 1 di dalam baris ke $-s$ dan unsur-unsur lainnya adalah 0. Dengan mempertukarkan kolom pada $E_{A}$ akan diperoleh matriks yang berbentuk $\left(\begin{array}{cc}I_{r} & J \\ 0 & 0\end{array}\right)$.Pada baris teratas dari $J$ dilakukan operasi kolom elementer kemudian dilanjutkan dengan baris kedua dan seterusnya sehingga diperoleh $Q$ yang merupakan hasilkali matriks-matriks elementer. Jadi, $P \times A \times Q=E_{A} \times Q=\left(\begin{array}{cc}I_{r} & 0 \\ 0 & 0\end{array}\right)$.

Teorema berikut menyatakan eksistensi dari matriks $X$ yang memenuhi $A \times X \times A=$ $A$ dengan $X=Q \times\left(\begin{array}{cc}I_{r} & 0 \\ 0 & D\end{array}\right) \times P$.

Teorema 3.7.Diberikan $A \in M_{m \times n}(S)$ dengan rank $=r$. Suatu matriks $X$ berukuran $n \times m$ memenuhi $A \times X \times A=A$ jika dan hanya jika

$$
X=Q \times\left(\begin{array}{cc}
I_{r} & 0 \\
0 & D
\end{array}\right) \times P
$$

untuk suatu $D \in M_{(n-r) \times(m-r)}(S), P \in M_{m \times m}(S)$ dan $Q \in M_{n \times n}(S)$ dengan $P$ dan $Q$ hasilkali matriks-matriks elementer, memenuhi

$$
P \times A \times Q=\left(\begin{array}{cc}
I_{r} & 0 \\
0 & D
\end{array}\right) .
$$

Bukti. $(\Leftarrow)$ Dari bentuk (3.1), diperoleh $A=P^{-1} \times\left(\begin{array}{cc}I_{r} & 0 \\ 0 & 0\end{array}\right) \times Q^{-1}$. Dapat ditunjukkan bahwa suatu $X$ yang diberikan dalam bentuk (3.2) memenuhi

$$
\begin{aligned}
& A \times X \times A=P^{-1} \times\left(\begin{array}{cc}
I_{r} & 0 \\
0 & 0
\end{array}\right) \times Q^{-1} \times Q \times\left(\begin{array}{cc}
I_{r} & 0 \\
0 & D
\end{array}\right) \times P \times P^{-1} \times\left(\begin{array}{cc}
I_{r} & 0 \\
0 & 0
\end{array}\right) \times Q^{-1} \\
= & P^{-1} \times\left(\begin{array}{cc}
I_{r} & 0 \\
0 & 0
\end{array}\right) \times\left(\begin{array}{cc}
I_{r} & 0 \\
0 & D
\end{array}\right) \times\left(\begin{array}{cc}
I_{r} & 0 \\
0 & 0
\end{array}\right) \times Q^{-1} \\
= & P^{-1} \times\left(\begin{array}{cc}
I_{r} & 0 \\
0 & 0
\end{array}\right) \times Q^{-1}=A .
\end{aligned}
$$

$(\Longrightarrow)$ Diberikan $A \times X \times A=A$.Dipunyai sifat bahwa $A \times X$ dan $X \times A$ adalah idempoten dan mempunyai rank yang sama dengan matriks $A$. Selanjutnya, $A \times X$ dan $X \times A$ mempunyai bentuk $\left(\begin{array}{cc}I_{r} & 0 \\ 0 & 0\end{array}\right)$. Oleh karena itu, terdapat matriks $R$ dan $Q$ yang merupakan hasilkali matriks-matriks elementer $R^{-1} \times A \times X \times R=\left(\begin{array}{cc}I_{r} & 0 \\ 0 & 0\end{array}\right)$ dan $Q^{-1} \times X \times A \times Q=\left(\begin{array}{cc}I_{r} & 0 \\ 0 & 0\end{array}\right)$.Akibatnya diperoleh,

$$
\begin{gathered}
R^{-1} \times A \times Q=R^{-1} \times A \times X \times A \times X \times A \times Q \\
=\left(R^{-1} \times A \times X \times R\right) \times R^{-1} \times A \times Q \times\left(Q^{-1} \times X \times A \times Q\right) \\
=\left(\begin{array}{cc}
I_{r} & 0 \\
0 & 0
\end{array}\right) \times R^{-1} \times A \times Q \times\left(\begin{array}{cc}
I_{r} & 0 \\
0 & 0
\end{array}\right) .
\end{gathered}
$$

Selanjutnya, $R^{-1} \times A \times Q$ mempunyai bentuk $R^{-1} \times A \times Q=\left(\begin{array}{ll}C & 0 \\ 0 & 0\end{array}\right)$ dan diperoleh $A=R \times$ $\left(\begin{array}{ll}C & 0 \\ 0 & 0\end{array}\right) \times Q^{-1}$, dengan $\operatorname{rank}(C)=\operatorname{rank}(A)$. Akibatnya, $P=\left(\begin{array}{cc}C^{-1} & 0 \\ 0 & 0\end{array}\right) \times R^{-1}$, maka

$$
P \times A \times Q=\left(\begin{array}{cc}
C^{-1} & 0 \\
0 & 0
\end{array}\right) \times R^{-1} \times R \times\left(\begin{array}{ll}
C & 0 \\
0 & 0
\end{array}\right) \times Q^{-1} \times Q=\left(\begin{array}{cc}
I_{r} & 0 \\
0 & 0
\end{array}\right) .
$$

Diberikan $Q^{-1} \times X \times P^{-1}$. Dipunyai, 


\section{Gregoria Ariyanti}

Akibatnya,

$$
\left(\begin{array}{cc}
I_{r} & 0 \\
0 & 0
\end{array}\right) \times Q^{-1} \times X \times P^{-1}=P \times A \times Q \times Q^{-1} \times X \times P^{-1} .
$$

$$
\left(\begin{array}{cc}
I_{r} & 0 \\
0 & 0
\end{array}\right) \times Q^{-1} \times X \times P^{-1}=P \times A \times X \times P^{-1}=\left(\begin{array}{cc}
I_{r} & 0 \\
0 & 0
\end{array}\right) .
$$

Dengan cara yang sama,

$$
Q^{-1} \times X \times P^{-1} \times\left(\begin{array}{cc}
I_{r} & 0 \\
0 & 0
\end{array}\right)=Q^{-1} \times X \times P^{-1} \times P \times A \times Q .
$$

Oleh karena itu, $Q^{-1} \times X \times P^{-1} \times\left(\begin{array}{cc}I_{r} & 0 \\ 0 & 0\end{array}\right)=Q^{-1} \times X \times A \times Q=\left(\begin{array}{cc}I_{r} & 0 \\ 0 & 0\end{array}\right)$.

Karena dipunyai $Q^{-1} \times X \times P^{-1}=\left(\begin{array}{cc}I_{r} & 0 \\ 0 & D\end{array}\right)$ untuk sebarang $D$, maka diperoleh

$$
X=Q \times\left(\begin{array}{cc}
I_{r} & 0 \\
0 & D
\end{array}\right) \times P .
$$

Teorema berikut menunjukkan syarat perlu dan syarat cukup $A \times x=b$ mempunyai penyelesaian dengan suatu matriks $X$ memenuhi $A \times X \times A=A$.

Teorema 3.8.Diberikan $A \in M_{m \times n}(S)$. Untuk $X$ suatu matriks yang memenuhi $A \times X \times A=A$, sistem persamaan linear $A x=b$ mempunyai penyelesaian $x=X \times b+(I-X \times A) \times \square$ dengan $h$ sebarang elemen $S$ jika dan hanya jika $A \times X \times b=b$.

Bukti. $(\Longrightarrow)$ Diberikan $A \in M_{m \times n}(S)$ dan $X$ suatu matriks yang memenuhi $A \times X \times A=A$. Sistem persamaan linear $A x=b$ mempunyai penyelesaian $x=X \times b+(I-X \times A) \times \square$ dengan $\square$ sebarang elemen $S$. Oleh karena itu, $A \times[X \times b+(I-X \times A) \times \square]=b$ sehingga $A \times X \times$ $b+A \times \square-A \times X \times A \times \square=b$. Selanjutnya diperoleh $A \times X \times b+A \times \square-A \times \square=b$. Dan, karena $A \times \square-A \times \square=0$, maka diperoleh $A \times X \times b=b$.

$(\Leftarrow)$ Diberikan $A \in M_{m \times n}(S)$ dan $\mathrm{X}$ suatu matriks memenuhi $A \times X \times A=A$. Diketahui $A \times X \times b=b$. Akibatnya,

$$
\begin{aligned}
A x= & A \times[X \times b+(I-X \times A) \times \square]-A \times X \times b+A \times(I-X \times A) \times \square \\
& =A \times X \times b+A \times I \times \square-A \times X \times A \times \square \\
& =A \times X \times b=b .
\end{aligned}
$$

Jadi, $A x=b$ mempunyai penyelesaian $x=X \times b+(I-X \times A) \times \square$ dengan $\square$ sebarang elemen $S$.

\section{KESIMPULAN}

Untuk $A \in M_{m \times n}(S), x \in M_{n \times 1}(S), b \in M_{m \times 1}(S)$ dengan $S$ semiring dan $\operatorname{rank}(A)=r$, disimpulkan syarat perlu atau syarat cukup penyelesaian sistem persamaan linear $A \times x=B$ sebagai berikut:

1. Terdapat matriks $P$ dan $Q$ yang merupakan hasilkali matriks-matriks elementer sehingga $P \times A \times Q=\left(\begin{array}{cc}I_{r} & 0 \\ 0 & 1\end{array}\right)$ dengan $I_{r}$ matriks identitas $r \times r$. 


\section{Gregoria Ariyanti}

2. Suatu matriks $X$ berukuran $n \times m$ memenuhi $A \times X \times A=A$ jika dan hanya jika $X=Q \times$ $\left(\begin{array}{cc}I_{r} & 0 \\ 0 & D\end{array}\right) \times P$, untuk suatu $D \in M_{(n-r) \times(m-r)}(S), P \in M_{m \times m}(S)$ dan $Q \in M_{n \times n}(S)$ dengan $P$ dan $Q$ hasilkali matriks-matriks elementer, memenuhi $P \times A \times Q=\left(\begin{array}{cc}I_{r} & 0 \\ 0 & D\end{array}\right)$.

3. Untuk $X$ suatu matriks yang memenuhi $A \times X \times A=A$, sistem persamaan linear $A \times x=b$ mempunyai penyelesaian $x=X \times b+(I-X \times A) \times \square$ dengan $\square$ sebarang elemen $S$ jika dan hanya jika $A \times X \times b=b$.

\section{REFERENCES}

[1] Anton, H., 2013. Elementary Linear Algebra: Applications Version/Howard Anton, Chris Rorres, 11 th edition. United States of America.

[2] Ariyanti, G., Suparwanto, A., and Surodjo, B., 2015. Necessary and Sufficient Conditionsfor The Solution of The Linear Balanced Systems in The Symmetrized Max PlusAlgebra. Far East J. Math. Sci. (FJMS), Vol. 97, No. 2, 253-266.

[3] Brewer, J.W., Bunce, J.W., and Van Vleck, F.S., 1986. Linear Systems over Commutative Rings. Marcel Dekker, New York.

[4] Brown, W. C., 1993. Matricesover Commutative Rings. Marcel Dekker, Inc., New York.

[5] Meyer, C. D., 2000. Matrix Analysis and Applied Linear Algebra. SIAM,Philadelphia. 